\title{
ASSOCIAÇÃO ENTRE CARACTERES DOS TUBÉRCULOS DE BATATA EM GERAÇÕES INICIAIS DE SELEÇÃO SOB CONDIÇÕES CONTRASTANTES DE TEMPERATURA
}

\author{
Guilherme Henrique Martins Rodrigues Ribeiro ${ }^{1}$, César Augusto Brasil Pereira Pinto ${ }^{2}$, \\ Izabel Cristina Rodrigues de Figueiredo ${ }^{3}$, Marcio Lisboa Guedes ${ }^{4}$, Carolina Mariane \\ Moreira $^{5}$
}

\footnotetext{
${ }^{1}$ Professor Adjunto, Centro de Ciências da Natureza, Universidade Federal de São Carlos (UFSCar), Campus Lagoa do Sino, Buri, São Paulo. E-mail: ghmribeiro@ufscar.br

${ }^{2}$ Professor Titular, Departamento de Biologia, Universidade Federal de Lavras (UFLA), Lavras, Minas Gerais.

${ }^{3}$ Pesquisador, Doutora em Genética e Melhoramento de Plantas, Área de Pesquisa e Desenvolvimento, PLANTAR S.A., Curvelo, Minas Gerais.

${ }^{4}$ Doutorando em Genética e Melhoramento de Plantas, Departamento de Biologia, Universidade Federal de Lavras (UFLA), Lavras, Minas Gerais.

${ }^{5}$ Professor Adjunto, Instituto Federal do Sul de Minas, Campus de Poços de Caldas, Poços de Caldas, Minas Gerais.
}

RESUMO: A eliminação de genótipos indesejáveis nas gerações iniciais de seleção proporciona economia de recursos nos programas de melhoramento. A correlação é uma ferramenta que auxilia na seleção precoce, ou na seleção indireta, através de caracteres correlacionados. O objetivo deste trabalho foi estimar a correlação entre os caracteres de aparência, produção e peso específico dos tubérculos, e avaliar a viabilidade da seleção precoce. Os experimentos foram realizados em casa de vegetação e em campo, sendo utilizadas famílias clonais oriundas de um dialelo parcial entre cultivares de boa aparência de tubérculos e clones tolerantes ao calor. Foram avaliados produtividade; peso específico e caracteres de aparência dos tubérculos; e, estimada a correlação entre os caracteres e entre as gerações. $\mathrm{O}$ formato dos tubérculos foi o caráter que apresentou maior correlação entre as gerações. Verificou-se forte correlação entre o formato dos tubérculos e defeitos como apontamento e curvatura, na primeira e segunda geração clonal conduzidas em campo. Para produtividade e peso específico dos tubérculos constatou-se boa correlação entre os experimentos conduzidos em casa de vegetação. Concluiu-se que a seleção precoce é eficiente para formato de tubérculos na geração de seedling; e, na primeira geração clonal, para formato de tubérculos, profundidade de olhos, e contra os defeitos apontamento e curvatura dos tubérculos.

Palavras-chave: Solanum tuberosum L. Seleção indireta. Melhoramento genético.

\section{ASSOCIATION BETWEEN POTATO TUBERS CHARACTERS IN EARLY GENERATIONS UNDER CONDITIONS OF CONTRASTING TEMPERATURES}

\begin{abstract}
Elimination of undesirable genotypes at the beginning of a breeding program provides resource savings and the correlation is a tool that assists in early selection or indirect selection through correlated traits. The aim of this study was to estimate
\end{abstract}

Cultura Agronômica, Ilha Solteira, v.25, n.3, p.253-266, 2016 
correlations between tuber appearance characters, tuber yield and tuber specific gravity, and assess the feasibility of early selection. In this study clonal families from a partial diallel design among cultivars with good tuber appearance and heat tolerant clones were used. Experiments were conducted under greenhouse and field conditions in the first generations. Characters related to tuber appearance, tuber yield and tuber specific gravity were assessed and correlations estimated between traits and between generations. Tuber shape was the trait with the highest correlation between generations. There was a moderate correlation between tubershape and defects such as pointing and curvature in the first and second clonal generations conducted in the field. For tuber yield and tuber specific gravity we found moderate correlations between experiments conducted in the greenhouse. It was found that early selection was efficient for tuber shape in the seedling generation and for tuber shape, eye depthness and against the defects pointing and curvature in the first clonal generation.

Key words: Solanum tuberosum L. Indirect selection. Breeding.

\section{INTRODUÇÃO}

No melhoramento genético da batata (Solanum tuberosum L.) diversos caracteres devem ser considerados pelo melhorista, desde aspectos relacionados com a produtividade e qualidade dos tubérculos, até caracteres relacionados à aparência dos tubérculos. Do ponto de vista de qualquer segmento de consumo de batata, a alta produtividade é uma condição necessária para o sucesso da cultivar. Alguns aspectos de qualidade dos tubérculos são particulares de cada segmento, como alto teor de matéria seca que é uma exigência da indústria de processamento e tubérculos com boa aparência, uma preferência do mercado para uso doméstico.

A aparência geral dos tubérculos é um caráter difícil de ser avaliado e melhorado devido sua complexidade (TAI, 1975) e por possuir grande número de caracteres difíceis de serem detectados (SILVA et al., 2007). Love et al. (1997) sugere como estratégia a decomposição da aparência geral em componentes individuais, devido a maior herdabilidade, o que levaria a uma maior eficiência na seleção.

As altas temperaturas comprometem o desenvolvimento da cultura da batata reduzindo a produtividade e o teor de matéria seca, e podem ainda, comprometer a aparência dos tubérculos provocando desordens fisiológicas como embonecamento e rachaduras (LEVY; VEILLEUX, 2007). Alguns estudos mostram que as altas temperaturas comprometem a textura da periderme dos tubérculos, tornando-as mais ásperas e com menos brilho (GINZBERG et al., 2005; GINZBERG et al., 2009). Estes autores relataram que temperaturas elevadas aumentam o número de células da periderme, reduzindo a elasticidade da pele fazendo com que ocorram fissuras, dando uma aparência áspera aos tubérculos. Outro efeito das altas temperaturas é a maior pressão de pragas e patógenos, como insetos, nematoides, fungos e bactérias (HAVERKORT; VERHAGEM, 2008), que também podem prejudicar a aparência dos tubérculos.

Cultura Agronômica, Ilha Solteira, v.25, n.3, p.253-266, 2016 
O melhoramento de batata se inicia com hibridações controladas, que originam milhares de sementes botânicas, que são semeadas e originam as plântulas, etapa conhecida por fase $\mathrm{S}$ ou geração seedling (GS). Geralmente a GS é conduzida em casas de vegetação, em recipientes de pequeno volume, e a primeira geração clonal (PGC) e segunda geração clonal (SGC), são conduzidas em campo (SILVA; PEREIRA, 2011). A seleção de genótipos superiores nas primeiras gerações pode proporcionar economia de recursos, como mão-deobra e insumos, e também, área de plantio nas gerações seguintes (SILVA; PEREIRA, 2011).

No entanto, a seleção no melhoramento da batata não é normalmente realizada nas primeiras gerações clonais ou na GS por ter sua eficiência questionável (SILVA et al., 2008). Por isso, busca-se métodos de seleção que sejam efetivos para se selecionar genótipos ainda na GS ou na PGC.

A associação entre caracteres pode ser utilizada para a seleção indireta, nas gerações iniciais de seleção, permitindo que um caráter complexo, difícil de ser avaliado e ou de baixa herdabilidade, possa ser melhorado pela seleção de componentes menos complexos, de alta herdabilidade e/ou de fácil medição (CRUZ et al., 2012). Diante do exposto, o objetivo deste trabalho foi estimar a correlação entre caracteres de aparência, produção e peso específico de tubérculos; e, avaliar a viabilidade da seleção precoce em batata.

\section{MATERIAL E MÉTODOS}

Para realização deste trabalho foram cruzados seis cultivares comerciais e oito clones do programa de melhoramento genético da batata da Universidade Federal de Lavras (PROBATATA-UFLA). Utilizou-se o esquema dialélico parcial incompleto (cultivares $\mathrm{x}$ clones) sendo produzidas 22 famílias clonais. As cultivares Caesar, Cupido, Markies, Monalisa, Vivaldi e Voyager foram selecionadas por apresentarem ótima aparência de tubérculos (i.e., pele amarelo-clara, lisa e brilhante, olhos rasos, formato alongado ou ovalado, polpa de cor creme, livre de desordens internas ou externas). Os clones do Programa de Melhoramento Genético de Batata (PROBATATA) CBM 04-48, CBM 07-78, CBM 16-16, CBM 22-19, SR1 07-16, SR2 21-02, SR2 35-05 e SR2 50-02 foram escolhidos por apresentarem tolerância ao calor (LAMBERT et al., 2006; BENITES et al., 2011).

As sementes botânicas foram semeadas em bandejas de isopor e posteriormente as plântulas foram transplantadas para vasos plásticos com volume de 0,5 L, contendo substrato organo-mineral Plantmax ${ }^{\circledR}$, para produzir a geração seedling (GS). De cada família foram cultivadas aproximadamente 100 plântulas nesta geração, em casa de vegetação, durante a safra de inverno no período de março a julho de 2011, sob condições de temperatura amenas. As plântulas foram cultivadas por aproximadamente 100 dias e na colheita tomaram-se dois tubérculos de cada seedling, e foram avaliados os caracteres aparência geral de tubérculos, profundidade de olhos (gemas) e aspereza da pele, empregando-se uma escala de notas, utilizando-se a média de notas atribuídas por três avaliadores, variando de 1 (pior desempenho) a 5 (melhor desempenho), e para formato do tubérculo de nota 1 para redondo a 5 para alongado.

Cultura Agronômica, Ilha Solteira, v.25, n.3, p.253-266, 2016 
A primeira geração clonal (PGC), composta pelos tubérculos colhidos nas plantas da GS, foi plantada simultaneamente em casa de vegetação e no campo na safra das águas (outubro de 2011 a março de 2012), em condições de temperatura elevada. No experimento conduzido em casa de vegetação os clones foram plantados em vasos de $3 \mathrm{~L}$ com substrato organo-mineral. $\mathrm{O}$ experimento realizado sob condições de campo foi plantado na fazenda experimental da EPAMIG, no município de Pouso Alegre - MG, em Latossolo VermelhoAmarelo de textura média, no espaçamento de $0,5 \times 0,8 \mathrm{~m}$. Tanto para o experimento em casa de vegetação como no campo foi tomada uma amostra aleatória de 30 clones por família, para cada experimento. Estes 30 clones foram divididos em três repetições no delineamento de blocos casualizados (DBC), ou seja, 10 clones diferentes em cada repetição, com uma única planta por clone. Os tubérculos colhidos das plantas da GS não utilizados nos experimentos da PGC foram multiplicados no campo para obtenção da segunda geração clonal (SGC).

Na PGC foram avaliados os seguintes caracteres dos tubérculos: formato (nota $1=$ redondo a nota $5=$ alongado), profundidade de olhos (nota $1=$ olhos profundos a nota $5=$ olhos rasos), defeitos: apontamento, achatamento, curvatura (nota 1 = defeito mais acentuado a nota 5 = ausência de defeito), aparência geral (nota $1=$ pior aparência a nota 5 = melhor aparência), aspereza da pele (nota $1=$ pele áspera a nota 5 = pele lisa). No experimento de campo, foram avaliados também a uniformidade de tamanho e de formato (nota 1 = pouco uniforme a nota $5=$ muito uniforme), a produtividade e o peso específico de tubérculos. Como nota para os caracteres de aparência dos tubérculos foi utilizada a média das notas atribuídas por três avaliadores.

O experimento da SGC também foi conduzido na mesma fazenda experimental da PGC, durante a safra de inverno, no período de junho a outubro de 2012. Foram avaliados os mesmos caracteres da PGC, sendo que as notas foram caracterizadas pela média das notas atribuídas pelos três avaliadores. Foram avaliados 20 clones tomados aleatoriamente de cada uma das 22 famílias oriundas da GS, totalizando 440 clones. Como foram tomados aleatoriamente, os clones utilizados neste experimento não foram necessariamente os mesmos utilizados nos experimentos da PGC. A SGC foi avaliada em um único experimento, plantado de forma a permitir simultaneamente a avaliação de clones e a avaliação de famílias.

O plantio foi realizado no espaçamento de $0,3 \mathrm{~m}$ entre plantas e $0,8 \mathrm{~m}$ entre linhas; e, cada parcela foi constituída de 5 plantas de cada um dos clones. Na avaliação de famílias cada parcela dos clones da família foi considerada uma repetição, totalizando 20 repetições por família, sendo o experimento avaliado no delineamento de blocos casualizados (DBC). Vale ressaltar que em cada repetição a família clonal era representada por um único clone. $\mathrm{Na}$ avaliação dos clones o experimento foi avaliado como blocos aumentados (DBA), com 20 blocos, utilizando-se como tratamentos comuns (testemunha) as cultivares Caesar e Voyager, e os controles tolerantes ao calor CBM 16-16 e CBM 22-19.

As temperaturas foram monitoradas em todas as gerações clonais, utilizando dados do Sistema Integrado de Dados Ambientais (SINDA), sendo que para os experimentos 
realizados em Lavras foram coletados dados na estação do próprio munícipio, e em Pouso Alegre os dados foram coletados da Estação de Santa Rita do Sapucaí (MG). Nos experimentos de campo da PGC e SGC na adubação foram utilizados $3500 \mathrm{~kg}$ de fertilizante formulado 04-14-08 ( $\left.\mathrm{N}, \mathrm{P}_{2} \mathrm{O}_{5}, \mathrm{~K}_{2} \mathrm{O}\right)$ no plantio e no momento da amontoa $400 \mathrm{~kg}$ de fertilizante formulado 20-05-20 em cobertura. O preparo de solo, manejo de irrigação e pulverizações com defensivos foram realizadas conforme a prática dos produtores na região.

Os resultados foram submetidos a análises de homogeneidade de variância (teste de Bartllet), de normalidade (Lilliefors) e análises de variância individuais. Estimou-se as correlações genéticas entre todos os caracteres em uma mesma geração e entre gerações empregando o software GENES (CRUZ, 2001).

\section{RESULTADOS E DISCUSSÃO}

Nos resultados das análises de variância verificou-se diferença significativa entre as famílias clonais, e a acurácia esteve acima de $80 \%$ para a maioria das características avaliadas. As exceções em ambos os casos foram para curvatura dos tubérculos na primeira geração clonal (PGC) no campo, e, uniformidades de tamanho e formato na segunda geração clonal (SGC). As correlações entre gerações e entre caracteres demonstram a associação entre as variáveis, além de ser um bom indicativo da herdabilidade (SILVA; PEREIRA, 2011). Segundo Carvalho et al. (2004) a correlação pode ser classificadas como nula $(\mathrm{r}=0)$; fraca $(0<|\mathrm{r}| \leq 0,3)$; média $(0,3<|\mathrm{r}| \leq 0,6)$; forte $(0,6<|\mathrm{r}| \leq 0,9)$; fortíssima $(0,9$ $<|\mathrm{r}| \leq 1)$ e perfeita $(|\mathrm{r}|=1)$. Baseado nesta classificação a maioria das correlações entre os caracteres de aparência dos tubérculos foram médias.

As temperaturas observadas durante a condução dos experimentos foram favoráveis ao desenvolvimento da cultura na GS e SGC (safra de inverno), sendo a porcentagem de horas com médias abaixo de $20{ }^{\circ} \mathrm{C}$ de $64,8 \%$ e $64,5 \%$, respectivamente. Segundo Levy e Veilleux (2007) temperaturas favoráveis para a cultura da batata está na faixa de 14 a $20{ }^{\circ} \mathrm{C}$, pois esta favorece a fotossíntese, reduz a respiração da planta e promove maior acúmulo de reservas. As temperaturas médias durante o ciclo da cultura foram de aproximadamente 18 ${ }^{\circ} \mathrm{C}$, e picos de $31^{\circ} \mathrm{C}$ na GS e de $35^{\circ}$ na SGC. No experimento da PGC, realizado na safra das águas, verificou-se situação oposta dos outros experimentos onde apenas $33,7 \%$ das horas tiveram temperaturas abaixo de $20^{\circ} \mathrm{C}$, sendo que a temperatura média observada em campo durante o experimento foi de $23^{\circ} \mathrm{C}$, com máximas de $27^{\circ} \mathrm{C}$ e picos de $34^{\circ} \mathrm{C}$.

Para os caracteres de aparência dos tubérculos avaliados na GS apenas formato apresentou uma correlação considerável com as gerações seguintes (Tabela 1). Estas correlações podem ser classificadas como forte entre a GS e a PGC, em ambos os ambientes, sendo superiores aos valores reportados por Silva et al. (2008). A correlação entre a GS e SGC, para formato de tubérculos foi fraca, sendo o valor encontrado muito inferior ao reportado por Silva et al. (2008). As diferenças entre o presente trabalho e de Silva et al. (2008), pode ser devido aos autores trabalharem com famílias obtidas de cruzamentos entre genitores contrastantes para os caracteres de aparência, e utilizarem os mesmos 45 clones de cada família na GS, PGC e SGC. Silva et al. (2008) ainda concluíram

Cultura Agronômica, Ilha Solteira, v.25, n.3, p.253-266, 2016 
que a seleção de famílias na GS pode ser realizada com maior pressão de seleção para formato de tubérculos.

Tabela 1. Correlação genética de formato (Form), textura da periderme (Pele), profundidade de olhos (Olho) e aparência geral dos tubérculos (Apg) de batata entre a geração de seedling (GS) e primeira geração clonal (PGC) avaliada em campo, PGC (c.v.) avaliada em casa de vegetação e segunda avaliação clonal (SGC) avaliada em campo.

\begin{tabular}{|c|c|c|c|c|}
\hline & Form & Pele & Olho & Apg \\
\hline PGC & $0,64^{* *}$ & $-0,12$ & 0,24 & $-0,32^{* *}$ \\
\hline PGC (c.v.) & $0,75^{* *}$ & $0,54^{* *}$ & 0,10 & $-0,37^{* *}$ \\
\hline SGC & 0,18 & $0,37^{* *}$ & $-0,18$ & $-0,17$ \\
\hline
\end{tabular}

Vale ressaltar que a GS foi conduzida em vasos de 0,5 L, restringindo o crescimento dos tubérculos. O tamanho do recipiente não possibilitou uma boa avaliação da aparência geral dos tubérculos, sendo as correlações com os demais ambientes negativas. Este resultado indica que a avaliação deste caráter não deve ser realizada na GS quando cultivada em recipientes que não permitam o adequado crescimento dos tubérculos. Em estudo conduzido por Veríssimo et al. (2012) visando avaliar a influência do tamanho do vaso sobre caracteres de aparência e rendimento na GS, os autores concluíram que recipientes maiores permitem melhor expressão da variabilidade das características. Os autores relatam que os vasos maiores proporcionam melhor expressão da variação genética de caracteres de aparência dos tubérculos, promovendo melhor eficiência na seleção precoce de famílias clonais.

O formato dos tubérculos está relacionado com a aptidão de uso, para a indústria de batata chips o ideal são genótipos com tubérculos de formato redondo, enquanto para préfrita congelada prefere-se mais alongados e para o uso doméstico o mais aceito seria um formato ovalado. Os resultados do trabalho apresentados na Tabela 1 sugerem a viabilidade de se realizar a seleção de famílias para formato dos tubérculos na GS, com sucesso. A seleção precoce de famílias para formato dos tubérculos já é relatada na literatura (AMARO et al., 2003; GOPAL, 1997; SILVA et al., 2008; SILVA et al., 2009). Assim, seleção precoce para formato de tubérculos poderia ser empregada de maneira a eliminar as famílias com formato indesejável para determinada aptidão de uso.

A seleção precoce de famílias para formato dos tubérculos já é relatada na literatura (AMARO et al., 2003; GOPAL, 1997; SILVA et al., 2008; SILVA et al., 2009) e os resultados do trabalho apresentados na Tabela 1 sugerem a viabilidade de se realizar a seleção de famílias para formato dos tubérculos na GS, com sucesso. Assim, seleção precoce para formato de tubérculos poderia ser empregada de maneira a eliminar as famílias com formato indesejável para determinada aptidão de uso. O formato dos tubérculos está relacionado com a aptidão de uso, para a indústria de batata chips o ideal são genótipos com tubérculos de formato redondo, enquanto para pré-frita congelada prefere-se mais alongados e para o uso doméstico o mais aceito seria um formato ovalado. 
A correlação para textura da periderme do tubérculo entre a GS e as seguintes, apresentou como de média magnitude, com a PGC cultivada em casa de vegetação (Tabela 1). Este resultado provavelmente ocorreu devido a ambos os ensaios terem sido conduzidos em casa de vegetação, utilizando substrato organo-mineral. Sabe-se que na textura da periderme do tubérculo tem grande influência do substrato de cultivo, sendo influenciada pela textura e teor de matéria orgânica. Nielsen (1968) trabalhou com a resposta da periderme a diferentes substratos de cultivo, verificou que a periderme dos tubérculos é afetada por temperatura, umidade, matéria orgânica e textura do solo.

A correlação fraca e negativa para a textura da periderme, entre a GS e a PGC, no campo, provavelmente ocorreu devido à presença de nematoides no solo/tubérculos, e as condições de altas temperaturas durante o experimento na PGC. A correlação da GS com SGC foi classificada como média, pois na SGC as condições ambientais, com temperaturas mais amenas, favoreceram a avaliação da textura da periderme. Ginzberg et al. (2005) verificaram que a temperatura tem grande efeito na textura da periderme dos tubérculos de batata, pois as altas temperaturas interferem no arranjo e na quantidade das células da periderme. Ginzberg et al. (2009) verificaram que as altas temperaturas do solo provocam pequenas fissuras entre as células da periderme, devido a um aumento no número de camadas protetoras, o que leva a uma maior rigidez da pele e com o crescimento dos tubérculos ocorre um rompimento entre as células dando um aspecto mais áspero aos tubérculos.

Tabela 2. Correlação genética de formato (Form), textura da periderme (Pele), profundidade de olhos (Olho), aparência geral dos tubérculos (Apg), apontamento (Apont), achatamento (Achat), curvatura (Curv), uniformidade de tamanho (UTam) e uniformidade de formato (UForm), entre os caracteres na primeira geração clonal no campo (PGC) e segunda geração clonal no campo (SGC).

\begin{tabular}{l|lllllllll}
\hline \multicolumn{1}{l}{} & Form & Pele & Olho & Apg & Apont & Achat & Curv & UTam & UForm \\
\cline { 2 - 10 } Form & $-0,07$ & 0,04 & $-0,00$ & $0,41^{* *}$ & $-0,58^{* *}$ & $0,28^{* *}$ & $-0,32^{* *}$ & 0,12 & 0,09 \\
Pele & $0,06^{* *}$ & 0,10 & $-0,20^{* *}$ & 0,06 & $-0,06$ & $0,28^{* *}$ & $-0,24^{* *}$ & $-0,10$ & $-0,24^{* *}$ \\
Olho & $0,16^{* *}$ & 0,01 & $0,30^{* *}$ & 0,04 & 0,11 & $-0,11$ & 0,10 & $-0,08$ & $-0,06$ \\
Apg & $-0,01$ & $0,18^{* *}$ & $-0,01$ & $0,32^{* *}$ & $-0,13$ & $0,21^{* *}$ & $-0,27^{* *}$ & 0,09 & $0,21^{* *}$ \\
Apont & $-0,56^{* *}$ & $-0,06^{*}$ & $-0,06^{* *}$ & $0,07^{*}$ & $0,45^{* *}$ & $-0,14^{*}$ & 0,05 & $-0,08$ & $-0,20^{* *}$ \\
Achat & $-0,03$ & 0,01 & $-0,14^{* *}$ & $0,09^{* *}$ & 0,01 & $0,34^{* *}$ & $-0,22^{* *}$ & 0,10 & 0,06 \\
Curv & $-0,36^{* *}$ & $-0,02$ & $-0,08^{* *}$ & 0,00 & $0,34^{* *}$ & $-0,04$ & $0,49^{* *}$ & $-0,09$ & $-0,04$ \\
UTam & $-0,05$ & $0,07^{* *}$ & $-0,05$ & 0,04 & 0,03 & 0,01 & $-0,01$ & $-0,31^{* *}$ & $0,28^{* *}$ \\
UForm & $0,05^{*}$ & 0,02 & $-0,02$ & $0,19^{* *}$ & $-0,04$ & 0,06 & $-0,07^{* *}$ & $0,17^{* *}$ & $-0,09$ \\
\hline
\end{tabular}

Correlação entre caracteres PGC no campo acima diagonal; SGC abaixo diagonal; entre gerações diagonal principal.

**** significativo a 5 e $1 \%$ respectivamente pelo teste de $\mathrm{t}$.

Entre a PGC e a SGC, cultivadas no campo, a correlação para o formato dos tubérculos foi fraca e negativa, mostrando ausência de associação entre as gerações (Tabela 2). Já para os dois ambientes de avaliação da PGC (campo e casa de vegetação), a 
correlação se mostrou favorável e de média magnitude (Tabela 3), mostrando que a seleção para este caráter na PGC pode ser realizada em casa de vegetação.

Para a textura da periderme a correlação entre a PGC e a SGC, cultivadas em campo, também foi fraca (Tabela 2), mostrando não haver associação entre as gerações. Tal diferença poderia ser explicada pela influencia da temperatura na formação da periderme como já mencionado. Entre os ambientes de cultivo da PGC, esta se mostrou de média intensidade e negativa (Tabela 3 ). Este resultado pode ser explicado pelas diferenças entre o teor de matéria orgânica no solo e no substrato organo-mineral, além da presença de nematoides no cultivo de campo.

Tabela 3. Correlação genética de formato (Form), textura da periderme (Pele), profundidade de olhos (Olho), aparência geral dos tubérculos (Apg), apontamento (Apont), achatamento (Achat) e curvatura (Curv), entre os caracteres de aparência dos tubérculos da PGC cultivada em casa de vegetação e em campo.

\begin{tabular}{l|ccccccc}
\hline \multicolumn{1}{l}{} & Form & Pele & Olho & Apg & Apont & Achat & Curv \\
\cline { 2 - 8 } Form & $0,53^{* *}$ & $-0,07$ & $-0,17$ & $-0,17$ & 0,02 & 0,13 & 0,06 \\
Pele & & $-0,39^{* *}$ & $-0,06$ & $0,43^{* *}$ & 0,01 & $-0,13$ & $-0,21^{* *}$ \\
Olho & & & $0,43^{* *}$ & $-0,04$ & $-0,03$ & $-0,04$ & 0,05 \\
Apg & & & & $0,25^{* *}$ & $-0,37^{* *}$ & 0,18 & $-0,45^{* *}$ \\
Apont & & & & & $0,34^{* *}$ & $-0,57$ & $0,27^{* *}$ \\
Achat & & & & & & 0,14 & $-0,17$ \\
Curv & & & & & & & $0,36^{* *}$ \\
\hline
\end{tabular}

Correlação PGC em casa de vegetação acima diagonal; entre PGC casa de vegetação e PGC campo diagonal principal.

*** significativo a 5 e $1 \%$ respectivamente pelo teste de $\mathrm{t}$.

A profundidade dos olhos apresentou correlações fracas entre a GS e as demais gerações (Tabela 1), mostrando não ser possível realizar seleção de famílias na GS para esta característica. Tal estimativa contraria os resultados de Silva et al. (2008), que encontraram uma correlação forte entre a GS e PGC, e uma fraca com SGC e sugere a seleção de famílias na GS. Estes autores sugeriram a seleção precoce para este caráter apoiados não só pela correlação entre as gerações, mas também pela análise de repetibilidade. As correlações para profundidade dos olhos entre a PGC e SGC (Tabela 2) e, entre os ambientes da PGC (Tabela 3), podem ser classificadas como médias.

Para a aparência geral dos tubérculos, todas as correlações entre a GS e as demais gerações foram negativas, sendo classificadas como médias para PGC, em ambos os ambientes, e fracas com SGC (Tabela 1). Estas correlações negativas mostram que devido à uma limitação de espaço para crescimento dos tubérculos na GS a avaliação realizada nesta geração não representou as famílias. No trabalho de Veríssimo et al. (2012) concluiu-se que vasos maiores proporcionaram uma melhor avaliação da aparência geral dos tubérculos.

Entre os ambientes de cultivo da PGC houve uma fraca correlação, para aparência geral dos tubérculos (Tabela 3). Este resultado pode ser explicado em parte pela complexidade da característica avaliada e por alguns contrastes entre os ambientes, como 
por exemplo, o volume do recipiente e o tipo de substrato. Segundo Tai (1975) a aparência geral dos tubérculos é um caráter complexo e de baixa herdabilidade. Na correlação entre a PGC e a SGC, ambas cultivadas em campo, a correlação foi média (Tabela 2). Neste caso, mesmo sendo cultivadas sobre condições de campo ainda existem diferenças que podem afetar a aparência geral dos tubérculos, como as condições de temperatura, o manejo da irrigação e diferenças nos atributos do solo.

Com relação aos defeitos no formato dos tubérculos (apontamento, achatamento e curvatura), as correlações entre PGC e SGC, cultivadas no campo (Tabela 2), e entre os ambientes de cultivo da PGC (Tabela 3) foram de média magnitude. A exceção foi para achatamento avaliado nos diferentes ambientes da PGC, que mostrou correlação fraca (Tabela 3), provavelmente devido à restrição de espaço do recipiente de cultivo na casa de vegetação. As correlações apresentadas indicam que seria possível realizar a seleção contra os defeitos apontamento, achatamento e curvatura já na primeira geração clonal.

Na correlação entre os caracteres de aparência, os coeficientes que se mostraram mais consistentes, apresentando a mesma magnitude, nos experimentos de campo foram entre formato dos tubérculos e apontamento e curvatura (Tabela 2). A correlação mostrou que quanto mais alongado o tubérculo maior a ocorrência destes dois defeitos (Tabela 2). Silva et al. (2009), encontraram correlações fortes e negativas entre formato e apontamento e formato e curvatura em experimentos realizados durante três anos, utilizando vinte famílias clonais.

Todas as correlações com aparência geral foram fracas, porém dois caracteres apresentaram uma tendência de contribuir para a melhoria da aparência dos tubérculos. O formato alongado e uma maior uniformidade de formato dos tubérculos parecem agradar aos avaliadores, que atribuíram notas melhores de aparência geral aos genótipos que apresentam estas características. No trabalho de Silva et al. (2009) as uniformidades de formato apresentaram correlação perfeita e a uniformidade de tamanho apresentou forte correlação com a aparência geral. Os autores comentam que maiores ganhos seriam obtidos na seleção de genótipos que apresentassem estas características. Ainda neste trabalho, a correlação entre formato e aparência geral foi negativa, devido ao fato dos tubérculos redondos não apresentarem defeitos como apontamento, achatamento e curvatura.

Com base na correlação entre as gerações iniciais e na repetibilidade entre gerações, Silva et al. (2008) recomendam a seleção de famílias, na GS para textura da periderme, profundidade de olhos, apontamento, achatamento e curvatura dos tubérculos. No entanto, a seleção de famílias em gerações iniciais para caracteres de aparência de tubérculos deve ser realizada com cautela, uma vez que a seleção baseada em um caráter individual pode afetar a seleção para os demais caracteres. Ao se realizar a seleção de famílias para o primeiro caráter a população será alterada, e a seleção para o segundo ficará comprometida, e assim por diante, podendo a seleção ser ineficiente e não encontrando famílias superiores. Talvez a melhor estratégia para seleção precoce de famílias seja a proposta por Amaro et al. (2003), em que apenas as piores famílias são descartadas. As melhores famílias contêm maior 
número de clones superiores e os poucos clones com bom desempenho dentro das famílias inferiores na sua grande maioria, não superam os melhores clones das melhores famílias.

No presente estudo alguns resultados interessantes foram obtidos para produtividade nas gerações iniciais, e entre ambientes de cultivo, sendo observada uma correlação forte e fortíssima da PGC cultivada em casa de vegetação com a PGC e SGC cultivadas em campo respectivamente (Tabela 4). Tal resultado fortalece a sugestão do cultivo da PGC em casa de vegetação, sendo possível fazer seleções para produtividade de tubérculos, desde que o recipiente utilizado não limite o crescimento dos tubérculos.

Praticamente o que se observou para as correlações entre a GS e a PGC e SGC, foi que estas foram fracas e muito semelhantes (Tabela 4), não sendo indicado a seleção para produtividade de tubérculos na GS. Trabalhando com componentes de produção Galarreta et al. (2006) obteve coeficientes semelhantes para produtividade entre a GS e PGC, e nulo ente GS e SGC, relatando a inviabilidade da seleção precoce para esta característica. Gopal (1997) encontrou correlações médias e significativas, entre a GS e a PGC e SGC, sendo de 0,56 e 0,34 respectivamente, que também não indicam a possibilidade de seleção na GS.

Tabela 4. Correlação genética de produtividade de tubérculos e peso específico dos tubérculos, entre a geração seedling (GS), primeira geração clonal em campo (PGC) e em casa de vegetação (PGC c.v.) e a segunda geração clonal (SGC).

\begin{tabular}{l|cccc}
\hline \multicolumn{1}{c}{ GS } & GS & PGC & PGC (c.v.) & SGC \\
\cline { 2 - 5 } PGC & & 0,24 & 0,26 & 0,22 \\
PGC (c.v.) & 0,23 & & $0,93^{* *}$ & $0,38^{* *}$ \\
SGC & $0,84^{* *}$ & 0,23 & & $0,61^{* *}$ \\
\hline
\end{tabular}

Correlação para produtividade de tubérculos acima da diagonal; correlação para peso específico dos tubérculos abaixo da diagonal.

*,** significativo a 5 e $1 \%$ respectivamente pelo teste de $\mathrm{t}$.

Na PGC uma fortíssima correlação foi encontrada, para produtividade dos tubérculos, entre os ambientes de cultivo (Tabela 4), podendo a seleção para este caráter ser realizada em casa de vegetação. As correlações entre a SGC e os ambientes de cultivo da PGC, mostraram magnitude média com o campo, e forte para casa de vegetação (Tabela 4), lembrando que as condições de temperatura foram diferentes entre as gerações. Este resultado reforça que a avaliação de famílias, na PGC, em casa de vegetação para produtividade de tubérculos pode ser uma opção. Embora a casa de vegetação não represente as reais condições de cultivo, pode representar uma economia de recursos e maior facilidade de condução do experimento. No trabalho de Galarreta et al. (2006) o coeficiente encontrado foi mais baixo, com valor de 0,22 , sendo considerado uma correlação fraca. $\mathrm{O}$ que tem sido relatado em alguns trabalhos é uma correlação média entre a PGC e SGC, a nível de famílias, sendo de 0,45 (LOVE et al., 1997), 0,50 (GOPAL, 1997) e 0,60 (BENAVENTE et al., 2011).

O peso específico de tubérculos também mostrou correlações fracas entre a GS e as PGC (campo) e SGC. Sabe-se que diversos fatores influenciam no peso específico dos 
tubérculos como, por exemplo, tipo de solo, teores de nitrogênio e potássio, manejo da irrigação e temperatura, condições que diferiram e podem ter influenciado negativamente entre a GS cultivada em casa de vegetação e a PGC e SGC cultivadas em campo. Bhering et al. (2009) avaliando o uso de marcadores para matéria seca e açucares redutores, relatou coeficientes semelhantes, para peso específico, entre a GS, também em casa de vegetação, e a PGC e SGC, cultivadas em campo. Correlações fracas entre a GS e a PGC e SGC sugerem cautela na seleção para este caráter.

Entre a GS e a PGC cultivada em casa de vegetação verificou-se uma correlação forte, sendo que apenas as condições de temperatura diferiram, sendo utilizado o mesmo tipo de substrato e o mesmo manejo de adubação e irrigação. Correlação média foi encontrada para a PGC cultivada em casa de vegetação, sob altas temperaturas, e a SGC, cultivada sob temperaturas amenas (Tabela 1). Os resultados das correlações entre a PGC (casa de vegetação) com as GS e SGC, sugerem um abrandamento dos efeitos do calor sobre o peso especifico dos tubérculos em condições de casa de vegetação. Todas as correlações com a PGC cultivada em campo foram fracas, lembrando que esta geração foi cultivada sob condições de calor. Estes resultados mostram que visando à seleção de famílias para tolerância ao calor, a melhor opção seria o cultivo sob condições reais no campo.

Amaro et al. (2003) estudando a eficiência da seleção precoce, avaliou o peso específico por meio de balança hidrostática e em solução salina, e cultivou a PGC em dois locais, Lavras, MG e Caldas, MG. Nos resultados apresentados pelos autores apenas foi observado uma correlação fraca entre a GS e a PGC em Lavras, por balança hidrostática. Os demais resultados mostram correlações médias entre as gerações, variando de 0,36 a 0,59. Estes autores concluíram que a seleção para este caráter deve ser branda, apenas eliminando as piores famílias. No trabalho de Benavente et al. (2011) também foram relatadas correlações médias entre a GS e as demais gerações, sendo 0,59 para PGC e 0,60 para SGC. Estes autores estudaram a repetibilidade da seleção em gerações precoces sobre as tardias, e concluíram que a seleção na GS para peso específico é mais eficiente que para produtividade.

\section{CONCLUSÃO}

É possível realizar a seleção para formato de tubérculos na geração seedling, direcionando as famílias de acordo com a aptidão de uso, desde que as plantas sejam cultivadas em recipientes que não limitem o crescimento dos tubérculos.

A seleção de famílias para os caracteres de aparência na geração seedling deve ser realizada com cautela, apenas eliminando as piores famílias.

Na primeira geração clonal a seleção para formato, profundidade de olhos, e contra os defeitos apontamento e curvatura dos tubérculos, além de produtividade pode ser realizada em casa de vegetação.

Cultura Agronômica, Ilha Solteira, v.25, n.3, p.253-266, 2016 


\section{AGRADECIMENTOS}

Ao $\mathrm{CNPq}$ pelo apoio financeiro e concessão de bolsa ao primeiro autor, e também à FAPEMIG pelo apoio financeiro para execução do projeto.

\section{REFERÊNCIAS BIBLIOGRÁFICAS}

AMARO G. B.; PINTO C. A. B. P.; LAMBERT, E. S.; MARTINS NETO L. L. Early selection of potato clones for tuber characters. Ciência e Agrotecnologia, Lavras, v. 27, n. 3, p.585-589, 2003.

BENAVENTE C. A. T.; PINTO, C. A. B. P.; FIGUEIREDO, I. C. R.; RIBEIRO, G. H. M. R. Repeatability of family means in early generations of potato under heat stress. Crop Breeding and Applied Biotechnology, Viçosa, v. 11, n. 4, p.330-337, 2011.

BENITES, F. R. G.; PINTO, C. A. B. P. Genetic gains for heat tolerance in potato in three cycles of recurrent selection. Crop Breeding and Applied Biotechnology, Viçosa, v. 11, n. 2, p.133-140, 2011.

BHERING, L. L.; PINTO, C. A. B. P.; BENITES, F. R. G.; LEITE, M. E.; SILVA, F. L. Seleção assistida por marcadores para teor de matéria seca e açúcares redutores em tubérculos de batata. Ciência Rural, Santa Maria, v. 39, n. 1, p.38-44, 2009.

CARVALHO, F. I. F.; LORENCETTI, C.; BENIN, G. Estimativas e implicações da correlação no melhoramento vegetal. Pelotas: Ed. Universitária da UFPel, 2004. 142 p.

CRUZ, C. D. Programa Genes: Aplicativo computacional em genética e estatística. Viçosa: UFV, 2001. 648 p.

CRUZ, C. D.; REGAZZI, A. J.; CARNEIRO, P. C. S. Modelos biométricos aplicados ao melhoramento genético. 4. ed.. Viçosa: UFV. 2012. v. 1, 514 p.

GALARRETA, J. I. R.; EZPELETA, B.; PASCUALENA, J.; RITTER, E. Combining ability and correlations for yield components in early generations of potato breeding. Plant Breeding, Westport, v. 125, p.183-186, 2006.

GINZBERG, I.; GERCHIKOV, N. Z. I. V. E.; FOGELMAN, E.; TANAMI, Z.; WARSCHAVSKY, S. Potato tuber skin development: the effect of hot climate. ISHS Acta Horticulturae, Amsterdam, v. 684, p.93-98, 2005.

GINZBERG, I.; BAREL, G.; OPHIR, R.; TZIN, E.; TANAMI, Z.; MUDDARANGAPPA, T.; DE JONG, W.; FOGELMAN, E. Transcriptomic profiling of heat-stress response in potato periderm. Journal of Experimental Botany, London, v. 60, n. 15, p.4411-4421, 2009.

GOPAL, J. Progeny selection for agronomic characters in early generations of a potato breeding programme. Theoretical and Applied Genetics, Berlin, v. 95, p.307-311, 1997.

HAVERKORT, A. J.; VERHAGEN, A. Climate change and its repercussions for the potato supply chain. Potato Research, Wageningen, v. 51, p.223-237, 2008.

Cultura Agronômica, Ilha Solteira, v.25, n.3, p.253-266, 2016 
LAMBERT, E. D. S.; PINTO, C. A. B. P.; MENEZES, C. B. Potato improvement for tropical conditions: I., analysis of stability. Crop Breeding and Applied Biotechnology, Viçosa, v. 6, n. 2, p.129-135, 2006.

LEVY, D.; VEILlEUX, R. E. Adaptation of Potato to High Temperatures and Salinity-A Review. American Journal of Potato Research, Orono, v. 84, p.487-506, 2007.

LOVE, S. L.; WERNER, B.K.; PAVEK, J. J. Selection for individual traits in the early generations of a potato breeding program dedicated to producing cultivars with tuber having long shape and russet skin. American Potato Journal, Orono, v. 74, p.199-213, 1997.

NIELSEN, N. K. An investigation of the regenerative power of periderm in potato tubers after wounding. Acta Agriculturae Scandinavica, The Hauge, v. 18, p.113-120, 1968.

SILVA, G. O.; PEREIRA, A. S.; SOUZA, V. Q.; CARVALHO, F. I. F.; FRITSCHE NETO, R. Correlações entre caracteres de aparência e rendimento e análise de trilha para aparência de batata. Bragantia, Campinas, v. 66, n. 3, p.381-388, 2007.

SILVA, G. O.; PEREIRA, A. S.; SOUZA, V. Q.; CARVALHO, F. I. F.; FRITSCHE NETO, R. Seleção para caracteres fenotípicos de tubérculos nas primeiras gerações em batata. Ceres, Viçosa, v. 55, n. 3, p.168-172, 2008.

SILVA, G. O.; PEREIRA, A. S.; SOUZA, V. Q.; CARVALHO, F. I. F.; FRITSCHE NETO, R. Correlações entre caracteres fenotípicos e análise de trilha para aparência e rendimento de batata. Ceres, Viçosa, v. 56, n. 1, p.63-68, 2009.

SILVA, G. O.; PEREIRA, A. S. Seleção em gerações iniciais para caracteres agronômicos em batata. Horticultura Brasileira, Piracicaba, v. 29, n. 4, p.499-455, 2011.

TAI G.C.C. Effectiveness of visual selection for early clonal generation seedling of potato. Crop Science, Madison, v. 15, n. 1, p.15-18, 1975.

VERÍSSIMO, M. A. A.; PEREIRA, A. S.; ANJOS, S. D.; TERRES, L. R.; NEY, V. G.; SILVA, G. O. Expressão de caracteres de tubérculos em função do tamanho de recipiente usado no cultivo de batata na geração de plântulas. Ceres, Viçosa, v. 59, n. 6, p.787-793, 2012.

Cultura Agronômica, Ilha Solteira, v.25, n.3, p.253-266, 2016 
